Open Access

\title{
Market efficiency of gold exchange-traded funds in India
}

Rupel Nargunam ${ }^{1 *}$ (D) and N. Anuradha ${ }^{2}$

\author{
* Correspondence: \\ rupelnargunam25@gmail.com \\ 'Department of Mathematics and \\ Actuarial Science, B S Abdur \\ Rahman Crescent University, \\ Chennai 600048, India \\ Full list of author information is \\ available at the end of the article
}

\begin{abstract}
Background: Gold exchange-traded funds, since introduction, are primarily aimed at tracking the price of physical gold in the financial market. This, a category of exchange-traded funds, whose units represent physical gold, is traded on exchanges like any other financial instrument. In the Indian financial market, gold exchange traded funds were introduced a decade ago to facilitate ordinary households' participation in the bullion market. They were also designed to assist in the price discovery mechanism of the bullion market.
\end{abstract}

Presentation of the hypothesis: In this paper, it is attempted to check if one of the constituents of price discovery mechanism, informational efficiency, has been achieved in gold exchange-traded funds' market. Information efficiency becomes evident only when all available information is reflected in the market price of the instrument.

Testing the hypothesis: Therefore, in order to assess the weak-form efficiency of the gold exchange-traded funds market, the daily returns of five gold exchangetraded funds traded on the Indian Stock Exchange over the period March 22, 2010, to August 28, 2015, were used. The non-parametric runs test, the parametric serial correlation test, and the augmented Dickey-Fuller unit root test are employed.

Implications of the hypothesis: The test results provide evidence that the efficient market hypothesis does not hold for the gold exchange-traded funds' market in India. Further, the test results address several underlying issues with respect to price discovery in the market under study and suggest that the Indian market for this derivative is not weak-form efficient. Hence, the factors affecting gold exchange traded-funds' market warrant the attention of the country's regulatory bodies, as appropriate legislation in support of market efficiency is needed.

Keywords: Exchange-traded funds, Gold exchange-traded funds, Efficiency, Stationarity, Price discovery, Market

\section{Background}

An exchange-traded fund (ETF) is a type of fund that spreads its ownership over a variety of assets such as shares of stock, corporate bonds, petroleum futures, gold ingots or foreign currency. Investors in ETFs are not exposed directly to the assets, but indirectly own them as their ownership is divided into shares and they are remunerated by the pay-offs that are usually a proportion of profits or a residual value when the fund is liquidated. In terms of transaction and remuneration, holding ETF shares is very similar to holding conventional shares of stock.

(c) The Author(s). 2017 Open Access This article is distributed under the terms of the Creative Commons Attribution 4.0 International License (http://creativecommons.org/licenses/by/4.0/), which permits unrestricted use, distribution, and reproduction in any medium, provided you give appropriate credit to the original author(s) and the source, provide a link to the Creative Commons license, and indicate if changes were made. 
Generally, ETFs investing in physical commodities that can be traded on a derivative market are called commodity ETFs. They usually focus on the commodity being traded and physically store it or invest in the derivative instruments that pertain to the commodity at hand. The other types of ETFs track the prices of assets or the assets' indices either directly or indirectly.

A gold exchange-traded fund (GETF) is a type of commodity ETFs; its primary task is to track the price of the underlying gold. The GETFs' underlying commodity are gold units that may be in paper form or in any other dematerialized form. These forms can be traded in the exchange like shares of a company. The main purpose of GETFs is to offer investors a platform to engage in the gold bullion market without coming in contact with the traded commodity itself. The strategy of GETFs is to track and reflect the price changes of physical gold with maximum transparency, not to invest in it. A GETF provides the investor with an opportunity to have an exposure in the gold market without actually trading physical gold.

GETFs are transparent derivative instruments, subject to stringent regulations in terms of investment norms and valuations. This assures the purity of gold that the fund invests in, facilitates accurate calculations of Net Asset Value, and thereby estimates the market price precisely. GETFs have helped retail investors because investment in small denominations is allowed. The minimum unit for trade is, however, one unit on the secondary market. This benefits the investor who may accumulate units over time and earn a higher profit than in the primary market. At the time of redemption, the pay-offs are either from the fund or from the derivative market. Further, compared with holding the physical commodity, by investing in dematerialized gold, the investor is able to enjoy various tax benefits. GETFs not subject to wealth tax.

The first gold exchange-traded product, the Central Fund of Canada, was introduced in 1961. It was further amended to include silver in 1983, which allowed investors to invest in silver along with gold. However, the first GETF, Gold Bullion Securities, was listed in 2003 on the Australian Securities Exchange.

In India, the Benchmark Asset Management Company Private Ltd was the first to put forward the concept of GETF. The first GETF was launched in May 2007, though it was initiated in May 2002 (Umarani and Deepa, 2015). Since then GETFs have been emerging as the best performers among traded assets. Risk-averse market participants have invested more in gold amid the declining stock prices. During the financial crisis and the recession that followed in the period 2008-09, GETFs generated returns as high as $34 \%$. GETFs have since become a very popular investment vehicle. In the fiscal year 2012-13, GETFs saw an inflow of Rs.1, 414 crores as well as an outflow of Rs. 2293 crores initiated by portfolio managers. In 2014-15, approximately Rs. 1475 crores was withdrawn from GETFs, followed by Rs. Nine hundred three crores in 2015-16. The outflow momentum in the fiscal year 2015-16 decreased due to static equity markets. Based on recent data acquired from the Association of Mutual Funds in India (AMFI), GETFs witnessed an outflow of Rs. Fifty One crores in September 2016, a value significantly lower than the outflow of Rs. One hundred eigthy three crores in July 2016, which was the highest recorded monthly outflow since June 2014, when Rs. Two hundred Tweenty crores was withdrawn from GETFs. The total outflow of capital during the first 5 months (April-August) of the current fiscal year 2016-17 was Rs. Four hundred sixty two crores. Market experts have attributed several reasons to these 
outflows: poor yield offered by investing in gold, continual price decreases, and a pessimistic outlook for gold on strong equity markets.

It has been a decade since ETFs were introduced in India, and as the financial market is planning to launch new derivative instruments pertaining to these ETFs, a performance analysis of this decade-old financial asset market is warranted. Was the purpose of introducing this class of investment asset met during the last 10 years? The GETF market is supposed to aid in price discovery in the gold bullion market.

When the GETF market is informationally efficient, investors are provided with a platform to participate in the gold bullion market. The market becomes efficient only when the market forces play an active role in the price discovery mechanism. It follows from the efficient market hypothesis that investors using a conventional investment strategy should not be able to habitually outstrip the market. If the market is efficient, fund managers can employ passive portfolio management, that is, an investment strategy where investors invest in certain securities over the long haul, the investment remains unaffected by fluctuations in the short-term securities market, and investors obtain normal returns. The goal of this paper is to empirically examine the efficiency of the GETF market in India.

Price discovery can be defined as a mechanism, which allows a buyer and a seller in a business proposition to move from establishing a general measure of overall prices to agreeing on a specific price (the optimum consumer basket which maximizes the utility function) for their transaction based on many factors including the size, location, and cost of the transaction. Price discovery is always a dynamic process and the true mission of any market or any exchange. The price discovery mechanism can be practically implemented through determining the market price of a security/commodity, good or service or through examining the market supply-demand and analyzing other aspects analogous with transactions. Trading on financial markets aims for obtaining the accurate prices. The price that is detected instantaneously on the ideal efficient market paves the way for a good evaluation of future risk and return. However, this price is usually not fixed, as new information is being perpetually generated in the economy and rapidly incorporated in the market prices. A dynamic market can be characterized as one in which the price discovery mechanism takes place momentarily as price changes are continuous; it will sometimes fall below the average and sometimes exceed the average as a result of market forces and the uncertainties surrounding the market.

This means that rational investors will not be able to consistently achieve abnormal profits above the conventional market returns, assuming that the information is made publicly available at the time of investment. Therefore, the term efficient market usually pertains to those markets that are said to be "informationally efficient". This means that buyers and sellers in any market have access to all the information required to agree on a price. However, in order to categorize and assess the competence of investors in a market, to assimilate the available information and react to it, economists make use of the following terms: weak-form, semi-strong and strong-form efficiency to differentiate between the degree of market efficiency based on the effectiveness of its price discovery mechanism. In weak-form efficient markets, no prognosis can be made about future prices from historical prices, hence, it can be said that the movement of prices resembles a random walk (Bodie et al., 2007). In the semi-strong form efficient markets, investors tend to respond promptly to any new information that enters the market so as to be able 
to correct the prevailing inefficiencies (Bodie et al., 2007). In strong-form efficiency markets, prices are expected to incorporate all public and private information and adjust promptly whenever new information penetrates the market (Brealey et al., 1999).

Market efficiency (or return predictability) is an important concept that highlights the speed of information dissemination and the actual scope for earning profits in commodity markets. Price discovery reflects the variation in asset prices reacting to the continual inflow of asset-related intrinsic information. Analogous assets are bought and sold in disparate markets. In evaluating the price discovery mechanism, the market in which the fundamental details are incorporated into prices most effectively may be identified.

Despite a greater emphasis on precious metals in the literature, more recently, there is a paucity of full-scale research examining the variability of the returns on investments in precious metals. This is an important field of study, rooted in the efficient market hypothesis (EMH), which stresses that prices should incorporate all available information and former prices cannot be used to predict returns (Malkiel and Fama, 1970). If returns on investments in precious metals can be anticipated, investors may benefit from the lack of return variability, this, in turn, would imply that the EMH does not hold. Therefore, the predictability of returns on investments in precious metals is remarkably intriguing to both academics and investors.

GETFs were introduced in India so that ordinary households could also trade in the bullion market in small denominations. A decade has passed since this financial instrument was floated and there are currently over 15 GETFs trading on the Indian Stock Exchange. It is thus expected that the market mechanism has been effectively achieved thereby leading to the efficiency of the market under study. However, there is no literature available to support or disprove this statement. The current paper attempts to fill this gap and tests the weak-form efficiency of the Indian GETF market.

\section{Literature review}

Amid uncertain economic conditions, effected by financial crises, precious metals are considered a store of wealth due to their intrinsic value. Over the centuries, gold, particularly because of its uniqueness when compared to a monetary unit, has operated as a reservoir of wealth, vehicle of exchange, and an item of merit (Goodman, 1956; Solt and Swanson, 1981). In addition, gold has a prominent role in that it acts as a "flightto-quality" asset during spells of political and economic crises or equity market failure and thus possesses exceptional portfolio diversification characteristics (Ciner, 2001). Moreover, gold been an investment vehicle over the ages because it acts as a hedge against inflation and a safe haven during economic crises (Cai et al., 2001; Baur and McDermott, 2010; Daskalaki and Skiadopoulos, 2011; Batten et al., 2014).

Empirical analyses of the price of gold in its various forms and the structure of the gold market structure have been a subject of interest among academics for many years. Gold prices are known to be highly responsive to exchange rate and inflation; this indicates that it can be the ideal investment option for hedging in periods of inflationary pressures and exchange fluctuations (Batten et al., 2010; Arouri et al., 2012). Investment in gold is considered to be a significant decision for any portfolio as this helps the investor in mitigating the risks that arise due to market fluctuations (Eswara, 2015). The gold market is highly liquid, which can be justified by the fact that many gold 
bullion investments have neither credit nor counterparty risk (Artigas, 2010). Recently, it has been observed that commodity markets have become similar to financial markets in some respects. According to Financial Stability Board and International Monetary fund, there has been a volley of warning shots that physical ETF risks could also be storing up a shock for the financial system. Bullion ETFs are convenient; provide exposure to one of the historically oldest forms of investments, while the gold that backs the fund is inventoried and the bar list is shown on the funds' websites. There are, however, several risks inherent in the structure and operation of ETFs. As a financial product, ETFs carry counterparty risk. In the past, these investment schemes were required to hold physical gold commensurate with the unit holders' investments. Currently, in response to the Indian government's initiative to satisfy gold demand using domestic resources, GETFs forward a portion of their holdings of physical gold. GETFs thus no longer possess all the gold their investors have paid for. The Reserve Bank of India authorized such advances of physical gold by designated bullion banks to jewelers and actual users. The current volume of physical gold trade is reckoned to be around 40 to $60 \mathrm{t}$. Thus the increasing activity of financial investors on both sides of trade transactions has created a kind of a financial trading sphere. While the increase in investing ventures is generally expected to fetch utility in terms of market efficiency, the current "financialization" of commodity markets escalates concerns similar to those in other financial markets (Domanski and Heath, 2007).

Gold has become a fairly reasonable option and a dominant commodity for investors looking for diversification and hedging in the financial market. Compared with other financial markets, venturing in gold has become commercially easier through the introduction of GETFs (Shafiee and Topal, 2010). Among the various forms of investment in gold, GETFs are better performing and more profitable (Velmurugan et al., 2013). As one of the most successful products introduced in the exchange, ETFs play a pronounced role in the Indian stock market. The ease of trading brought about by GETFs has increased the volatility of gold (Baur, 2013). In addition, the attractiveness of gold as an investment is growing fast, after the gold exchange traded products were introduced (Shafiee and Topal, 2010). GETFs relate closely with market stability and volatility (Aggarwal and Schofield, 2013). However, prices of ETF are less volatile in the Indian stock market (Goyal and Joshi, 2011). More recently, investors have come to prefer more of these products. GETFs have triggered the appetite for gold, which has become an investment vehicle that trades as easily as a stock or share (World Gold Council, 2008). Gold price appreciation in the long term has led to an upsurge in the quantity of this asset demanded by investors, ceteris paribus. This is a consequence of price projections employing the rationale of information disseminated through prices and proves to be the reason for the positive slope of the gold investment demand curve over a prevalent range of price levels (Sazonov and Nikolaev, 2013). GETFs unit prices move in tandem with the equity stock market prices and have a negative correlation with equity investments (Mukesh et al., 2012). This negative correlation allows GETF units to be included in any investment portfolio for risk diversification (Goyal, 2014). Over-estimation and under-estimation are reasons for the gold curve to have a negative slope (Sazonov and Nikolaev, 2013).

The ability to predict future returns has been compared to finding the pot of gold at the end of the rainbow. The traditional approach to asset management assumes that 
prices follow a random walk. This framework presumes that the rates of return required by investors are invariable and any future returns remain unforecastable. However, the literature is swamped with research disproving the inferences of the random walk hypothesis.

There is evidence of positive dependence in returns on gold and silver, but investors cannot easily capitalize on the dependence (Solt and Swanson, 1981). When studying the daily, weekly and monthly gold and silver prices from January 1970 to December 1989, the information incorporated in the past prices of gold and silver does not allow for prices predictions in the short run: long-term predictions, however, are credible and compared with silver, gold demonstrates a greater magnitude of dependence (Lashgari, 1992). The long memory behavior of gold returns is unstable (Cheung and Lai, 1993). If asset prices do not follow a random walk, investor psychometrics leads the return generating process so that the historical sequence can predict future returns (Worthington and Higgs, 2006). The fundamental behavior applicable to physical gold and silver returns also applies to gold and silver ETF prices and returns. Specifically, their price movements do not conform to a random walk. The inefficiency, which was not exploitable with investments in physical gold and silver in the past, now provides an opportunity for abnormal returns through a simple filter-trading rule (Naylor et al., 2011).

Estimation errors in the gold market usually overreact to observed spot price fluctuations but underreact to streams of gold from ETFs (Aggarwal et al., 2014). When compared to other investment markets, gold markets provide the highest average return for less total and systematic risk (Goyal, 2014). GETFs track their underlying asset closely, as is evident from their tracking error and pricing deviation measurements (Narend and Thenmozhi, 2014). The advent of ETFs investing in gold and commodities, in general, has affected the price of the underlying assets (Baur, 2013). By minimizing the tracking error between the fund and the underlying asset, GETFs generate returns identical to returns offered by the domestic price of gold via investment in physical gold (Reddy et al., 2014). The tracking error for GETFs was roughly $0.3422 \%$ in 2011 . The gold market is weakform efficient (Aggarwal and Soenen, 1988). While inefficiency is present in the gold and silver ETF markets on New York Stock Exchange when risk is factored, the abnormal returns evaporate, specifically; these markets' price movements do not follow a random walk (Naylor et al., 2011). Further, in India, the performance of GETFs is superior to other mutual fund investments particularly in the post-crisis period (Eswara, 2015). In sum, it can be said that there is an association between the GETF and the bullion markets. However, the literature on the market efficiency of GETFs in India since their introduction is scarce. The current study addresses this scarcity. Its objective is to explore whether the Indian GETF market is weak-form efficient.

\section{Methods}

In this study, five GETFs were considered: SBI Gold Exchange Traded Scheme, UTI GETF, Kotak GETF, R*Shares GETF, Goldman Sachs Gold Exchange Traded Scheme. The daily returns of GETFs over the period 2010 to 2015 were used. These GETFs have been floated and traded on the Indian Stock Market (BSE) since the year when GETFs was first introduced in India (i.e., in 2007). The historic data on the GETFs of both banking and non-banking institutions were considered. The closing prices were available only from 22/03/2010 onwards; hence, the daily returns in the period from 22/03/ 
2010 to $28 / 08 / 2015$ were used. The returns, calculated as differences in the log price, were used to examine the efficiency of the market. If the returns based on the GETF prices followed a random walk, it could be concluded that the Indian GETF market was informationally efficient in the weak form. The daily returns were analyzed for randomness using both non-parametric and parametric tests. Even if parametric tests are available, both types of tests are employed in this paper.

Firstly, non-parametric tests, namely the runs test were performed. Parametric tests in this paper comprise a correlogram method, unit root test. The non-parametric version of the unit root test namely the Philips-Perron test was not performed.

The runs test can be used to check if the given data set was generated by a random process or not (Bradley, 1968). The test follows a non-parametric approach that allows discovering statistical interrelationships that may not be found via an auto-correlation test. Here, the null hypothesis is that the observed data sequence conforms to a random pattern, against the alternative that it does not. The test statistic is calculated as:

$$
Z=\frac{(R-\bar{R})}{S_{R}}
$$

where;

$\mathrm{R}$ is defined as the observed number of runs,

$\bar{R}$ is defined as the expected number of runs, and $S_{R}$ is defined as the standard deviation of the number of runs.

If the Z-value is greater than -1.96 and lower than +1.96 , it is considered statistically significant, suggesting that prices of the security follow no particular pattern. However, if the Z-value is lower than -1.96 or higher than +1.96 , the value of the test statistic will be considered not statistically significant indicating that the security prices, contrary to the initial expectation, do not conform to a random walk.

A value of the test statistic of the runs test greater than the critical value at a particular level of significance indicates non-randomness in the daily returns under analysis and suggests that the Indian GETF market is not weak-form efficient. On the other hand, a value of the test statistic below the critical value at a particular level of significance indicates random daily returns and suggests that the Indian GETF weak-form market is efficient.

Secondly, in time series data analysis, a correlogram is used to provide a representation of the interdependence of the data under analysis as it plots the autocorrelations against the time lags. The plot of the autocorrelation function or correlogram ought to converge to zero geometrically if the series is stationary (Enders, 2008). It is a graph demonstrating the magnitude of correlations in the data at different time intervals, thus revealing the existence of cycles and their phases.

Unlike for a non-stationary process, the patterns, that is, the length of the autocorrelations or serial correlations plotted in the correlogram die away rather quickly for a stationary process. This means that if the correlogram bars do not disappear quickly the daily returns are random and the Indian GETF market is weak-form efficient. On the other hand, if the correlogram bars die out rather quickly, the data under analysis can be considered stationary. This supports the conclusion that the daily returns are not random and the Indian GETF is not weak-form efficient. 
The third method to examine market efficiency is testing for the presence of a unit root. A unit root test can be used for such examination (Hassan et al., 2007) because market efficiency stipulates randomness (non-stationary) in the prices of securities. In the econometrics literature, the unit root test, also known as the augmented Dickey-Fuller (ADF) test, is commonly used for investigating stationary behavior. By way of explanation, the terms non-stationary, random walk, and unit root may be considered as synonymous (Damodar, 2003). The unit root examines whether the financial time series under analysis is non-stationary. If the test statistic is lower than the critical value, then the null hypothesis is rejected; the data is not non-stationary. In this study, the ADF test was chosen to test for the presence of a unit root.

$$
\Delta \rho_{i t}=\alpha_{0}+\alpha_{1} t+\rho_{0} \rho_{i t-1}+\sum_{i=1}^{q} \rho_{i} \rho_{i t-1}+\epsilon_{i t},
$$

where $\rho_{i t}$ denotes the price of the $i$-th GETF at time $t$, and,

$$
\Delta \rho_{i t}=\rho_{i}+\rho_{i t-1}
$$

where;

$\rho_{i}$ are coefficients to be determined,

$q$ is the number of lagged terms,

$t$ is the trend term,

$\alpha_{1}$ is the estimated coefficient for the trend, and

$\alpha_{0}$ is a white noise constant.

A value of the ADF test statistic below the critical value at a particular level of significance, indicates that the daily returns under analysis are stationary implying that the Indian GETF market is not weak-form efficient. On the other hand, if the value of the test statistic is greater than the critical value at a particular level of significance, the daily returns are not stationary; hence, it can be concluded that the Indian GETF market is weak-form efficient.

\section{Results}

The historical closing prices of the derivative instruments under analysis have a very large standard deviation and are negatively skewed. Therefore, in order for the tests to deliver meaningful results, the differences between the logarithms of the closing prices

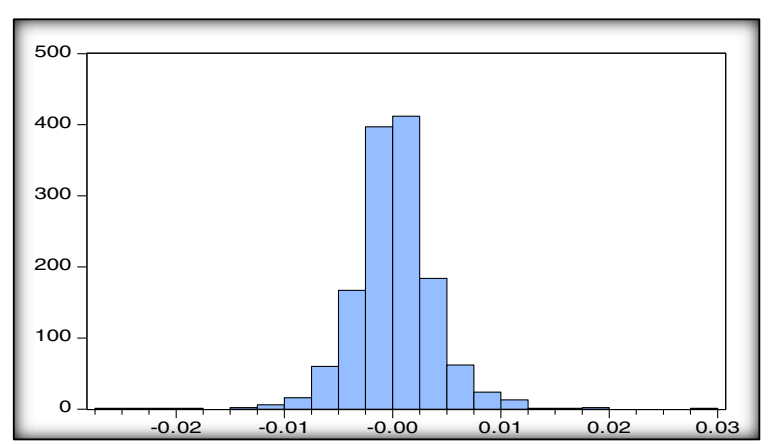

Fig. 1 Histogram representing the difference in log price of SBI GETF. In the histogram, the horizontal axis represents the difference in log price and the vertical axis represents the number of times each value occurs, i.e.: it is the probability density function of the difference in log price of SBI GETF 


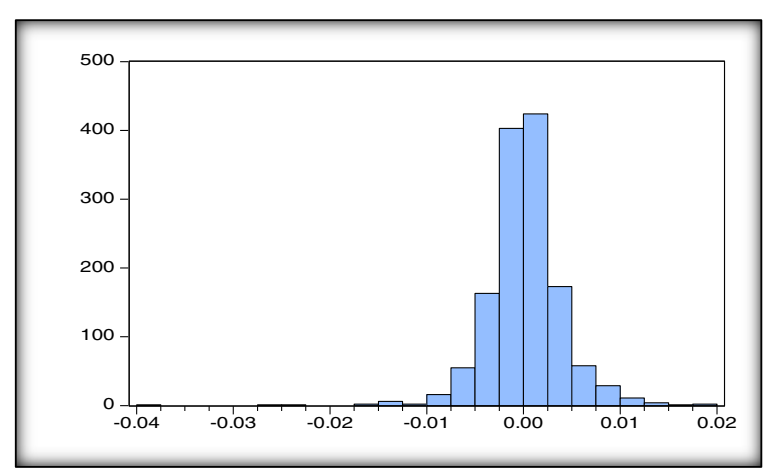

Fig. 2 Histogram representing the difference in log price of GOLDMAN SACHS GETF. In the histogram, the horizontal axis represents the difference in log price and the vertical axis represents the number of times each value occurs, i.e.: it is the probability density function of the difference in log price of GOLDMAN SACHS GETF

are used to bring the distribution of the values in the data set under analysis closer to normal.

It is evident from Figs. 1, 2, 3, 4 and 5 that the returns data under analysis conform to the normal distribution, which allows for the tests performed to produce meaningful results.

The descriptive statistics for the returns data, calculated as differences in log prices are tabulated in Table 1.

In addition to the normal distribution of data inferred from Figs. 1, 2, 3, 4 and 5, Table 1 shows that the values' standard deviation is very small.

The runs test was performed for daily returns under the assumption that the observed number of runs approximately follows the normal distribution. Displaying the absolute value of the standard normal variate (denoted $|\mathrm{Z}|$ ) the results of the runs test using daily returns are presented in Table 2 .

Table 2 shows that the $|Z|$ values for all five GETF data series are greater than 1.96 . Since the values of the test statistic are greater than the critical value at the $5 \%$ point of $\mathrm{N}(0,1)$, it can be deduced that the price changes are not random at the $5 \%$ level of significance. Further, the results from this test confirm that past prices affect future prices and can hence be used to anticipate future price variations. The previous literature

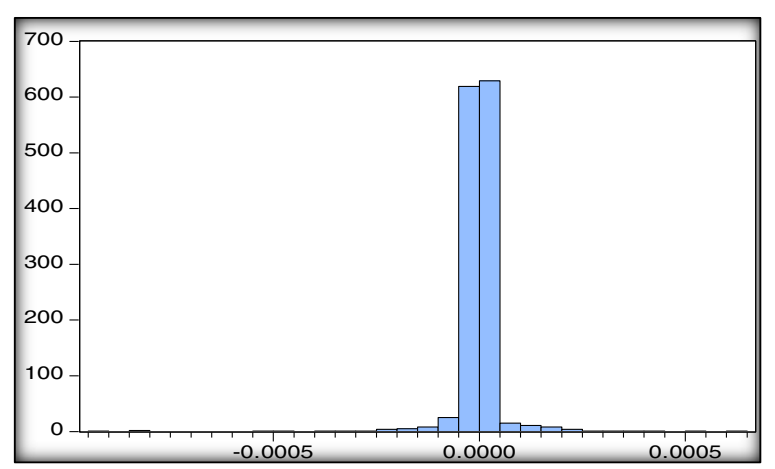

Fig. 3 Histogram representing the difference in log price of KOTAK GETF. In the histogram, the horizontal axis represents the difference in log price and the vertical axis represents the number of times each value occurs, i.e.: it is the probability density function of the difference in log price of KOTAK GETF 


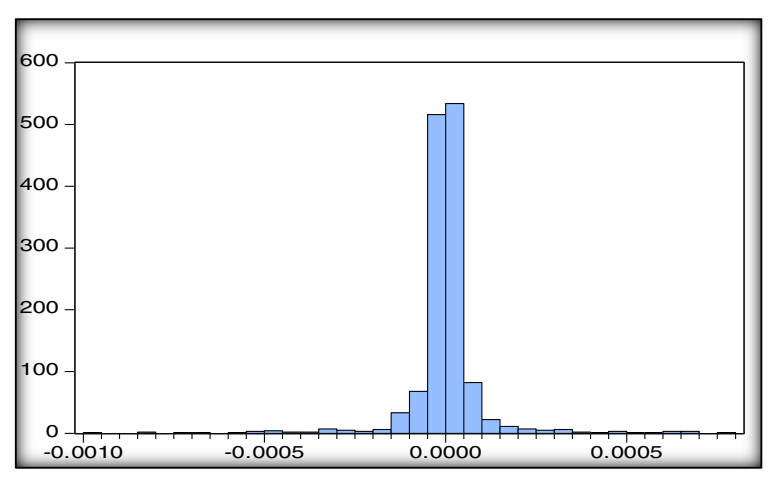

Fig. 4 Histogram representing the difference in log price of $R^{*}$ SHARES GETF. In the histogram, the horizontal axis represents the difference in log price and the vertical axis represents the number of times each value occurs, i.e.: it is the probability density function of the difference in log price of R*SHARES GETF

contains examples in which based on the results from the runs test, it has been concluded that successive price changes are not random (Elango and Hussein, 2008).

The correlogram values for the log-transformed daily returns are tabulated with two lags since the value of the auto correlation changes from negative to positive in two lags.

In Figs. 6, 7, 8, 9 and 10, the auto correlation and partial auto correlation quickly fade away for all the five GETFs under analysis. The pattern exhibited by the correlogram plot indicates that the data under analysis is stationary. Further, the correlogram test shows that the auto correlation coefficient lies between -1 and +1 and the values are very small for all five GETF data series. The Ljung-Box Q-test statistics are also significant at $5 \%$ significance level. This means that there is auto correlation and the null hypothesis of autocorrelation, can be accepted. Hence, the subsequent price changes are not random and may be used to estimate future price changes. In sum, the results from this test also indicate that past data affect the future data.

The unit root test used the log-transformed of daily returns of all five funds under analysis. The GETF return data were tested under all three main versions of the test: (i) test for unit root, (ii) test for a unit root with drift, (iii) test for a unit root with drift and deterministic time trend.

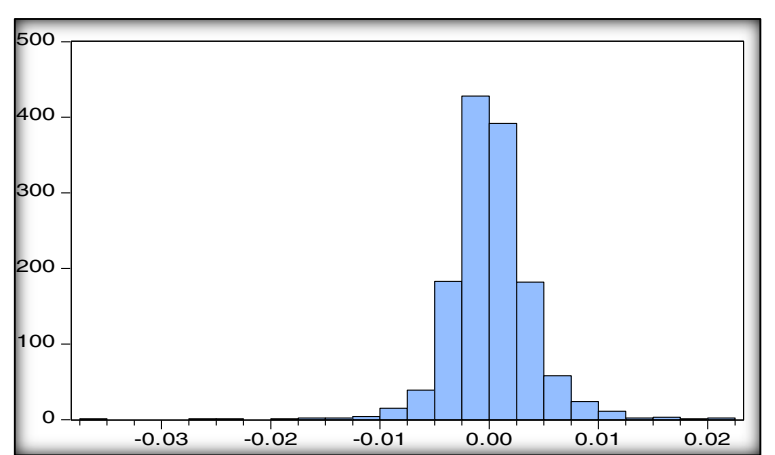

Fig. 5 Histogram representing the difference in log price of UTI GETF. LEGEND: In the histogram, the horizontal axis represents the difference in log price and the vertical axis represents the number of times each value occurs, i.e.: it is the probability density function of the difference in log price of UTI GETF 
Table 1 Descriptive statistics of returns

\begin{tabular}{llllll}
\hline Statistical & \multicolumn{5}{l}{ GETFs UNDER ANALYSIS } \\
\cline { 2 - 6 } measure & SBI & UTI & KOTAK & GOLDMANSACHS & R*SHARES $^{*}$ \\
\hline MEAN & 0.000127 & 0.000123 & $-1.12 \mathrm{E}-06$ & 0.000128 & $-4.15 \mathrm{E}-07$ \\
MEDIAN & $9.11 \mathrm{E}-05$ & $-2.70 \mathrm{E}-06$ & $1.68 \mathrm{E}-08$ & $8.98 \mathrm{E}-05$ & $2.41 \mathrm{E}-07$ \\
MAXIMUM & 0.028331 & 0.021802 & 0.000626 & 0.018683 & 0.000778 \\
MINIMUM & -0.2519 & -0.036579 & -0.000915 & -0.03772 & -0.000967 \\
STD. DEV. & 0.00384 & 0.003922 & $6.47 \mathrm{E}-05$ & 0.003972 & 0.00011 \\
\hline
\end{tabular}

The probability values of the ADF unit root test using the log-transformed daily returns are presented in Table 3.

In Table 3, the results of the ADF test for all five GETFs show that the $P$-values in all three forms of the test equation are significant at the $5 \%$ level. The $P$-values are less than $5 \%$ level, hence, the null hypothesis can be rejected at the 5\% significance level and the data series do not have a unit root. This means that the data is stationary, and therefore, not random in nature, so the subsequent price changes are not random and could be used to estimate future price changes. Past data is thus shown to affect future data. A similar study using the ADF test in the context of the Indian stock market also rejected the null of unit root presence (Gupta and Basu, 2011).

All the tests performed to assess the randomness of the returns show that the GETF returns are not random in nature and can be used to predict future returns.

\section{Discussion}

From among exchange-traded commodities (ETCs), exposure to gold is around 65\% while the other commodities comprise the remaining 35\%. The reason for gold's dominance can be partially attributed to the fact that it was the first ETC to be created. In addition, participants can easily access information about the general market for gold before making their investment decisions. There are many studies on the factors affecting precious metal markets. The determinants of changes in market conditions include international institutional and macroeconomic factors, namely, the instability of interest rates, the trade cycle, pecuniary environment as well as geopolitical agitations around the world, which may disrupt market stability. The aftermath of these incidents tends to reverberate in the minds of market participants as well as in the price discovery mechanism of the market, and consequently lead to discrepancies in the serial correlation of returns (Charles et al., 2015).

Theoretically, weak-form efficiency means that all historic price and return information is wholly and immediately incorporated into the market price. Consequently, the returns are entirely incalculable, and no investor is capable of earning supernormal

Table 2 Runs test values for daily returns of GETF

\begin{tabular}{lc}
\hline NAME OF GETF & $|Z|$ VALUE \\
\hline SBI & 3.428 \\
KOTAK & 18.065 \\
UTI & 14.528 \\
GOLDMAN SACHS & 20.568 \\
R*SHARES & 22.309 \\
\hline
\end{tabular}




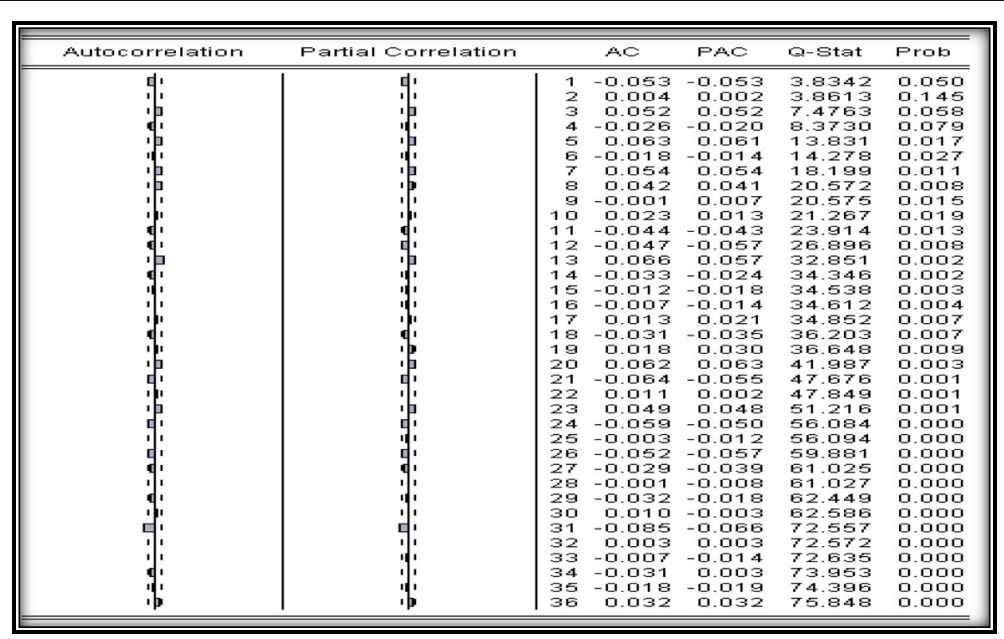

Fig. 6 Correlogram of SBI GETF. The correlogram displays a character-based plot of the Autocorrelations, Partial autocorrelations and the Portmanteau (Q) statistics of the difference in log price of SBI GETF

profits persistently over a period of time by utilizing the past prices (Fama, 1970). This characteristic of a dynamic market implies guaranteed benefits to market players who regard precious metals as assets worthy of investment on the basis of diversification, hedging, and risk management.

The Union Budget of India 2005-06 announced the introduction of GETFs and the creation of a market for them in India. It also suggested that upon consultation with the Reserve Bank of India, the Securities and Exchange Board of India should encourage mutual funds to introduce ETFs with gold as the underlying asset so as to empower households to buy and sell gold in units of a very low denomination.

The purpose of introducing derivative instruments with gold, as the underlying asset is to mobilize the surplus gold holdings held by Indian households and institutions, and thus reduces import dependence. Imports of gold, which were only second to oil,

\begin{tabular}{|c|c|c|c|c|c|}
\hline Autocarrelation & Partial Correlation & AC & PAC & Q-Stat & Prab \\
\hline 拝 & 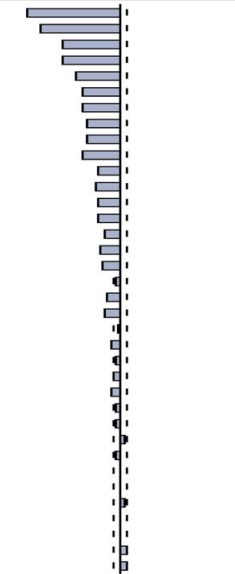 & 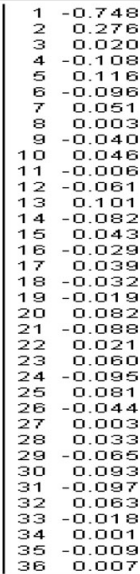 & 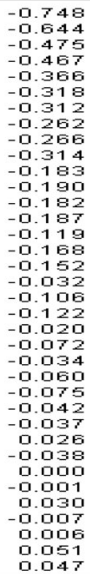 & 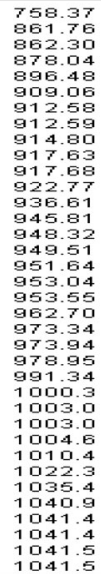 & $\begin{array}{l}\text { a.ono } \\
0.000 \\
0.000 \\
0.000 \\
0.000 \\
0.000 \\
0.000 \\
0.000 \\
0.000 \\
0.000 \\
0.000 \\
0.000 \\
0.000 \\
0.000 \\
0.000 \\
0.000 \\
0.000 \\
0.000 \\
0.000 \\
0.000 \\
0.000 \\
0.000 \\
0.000 \\
0.000 \\
0.000 \\
0.000 \\
0.000 \\
0.000 \\
0.000 \\
0.000 \\
0.000 \\
0.000 \\
0.000 \\
0.000 \\
0.000 \\
0.000 \\
0.000 \\
0.000\end{array}$ \\
\hline
\end{tabular}

Fig. 7 Correlogram of GOLDMAN SACHS GETF. The correlogram displays a character-based plot of the Autocorrelations, Partial autocorrelations and the Portmanteau (Q) statistics of the difference in log price of GOLDMAN SACHS GETF 


\begin{tabular}{|c|c|c|c|c|c|c|}
\hline Autacarrelation & Partial Correlation & & $\mathrm{AC}$ & PAC & Q-Stat & Prab \\
\hline 留 & 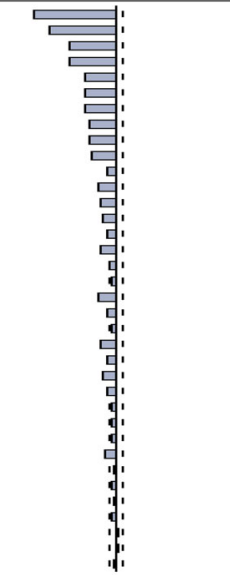 & $\begin{array}{r}1 \\
2 \\
3 \\
4 \\
5 \\
6 \\
7 \\
8 \\
9 \\
10 \\
11 \\
12 \\
13 \\
14 \\
15 \\
15 \\
17 \\
13 \\
19 \\
20 \\
21 \\
22 \\
23 \\
24 \\
25 \\
26 \\
27 \\
28 \\
29 \\
30 \\
31 \\
32 \\
33 \\
34 \\
35 \\
36\end{array}$ & $\begin{array}{r}-0.674 \\
0.155 \\
0.053 \\
-0.097 \\
0.1093 \\
-0.087 \\
0.045 \\
0.007 \\
-0.040 \\
0.048 \\
-0.015 \\
-0.059 \\
0.103 \\
-0.073 \\
0.026 \\
-0.017 \\
0.037 \\
-0.040 \\
-0.010 \\
0.084 \\
-0.095 \\
0.020 \\
0.066 \\
-0.091 \\
0.070 \\
-0.039 \\
0.001 \\
0.030 \\
-0.053 \\
0.082 \\
-0.093 \\
0.057 \\
-0.005 \\
-0.008 \\
-0.013 \\
0.012\end{array}$ & $\begin{array}{l}-0.074 \\
-0.546 \\
-0.372 \\
-0.376 \\
-0.259 \\
-0.256 \\
-0.252 \\
-0.210 \\
-0.225 \\
-0.194 \\
-0.073 \\
-0.155 \\
-0.131 \\
-0.114 \\
-0.079 \\
-0.128 \\
-0.059 \\
-0.040 \\
-0.152 \\
-0.079 \\
-0.039 \\
-0.130 \\
-0.077 \\
-0.119 \\
-0.078 \\
-0.041 \\
-0.049 \\
-0.033 \\
-0.087 \\
-0.013 \\
-0.031 \\
-0.014 \\
-0.037 \\
0.012 \\
0.019 \\
-0.024\end{array}$ & 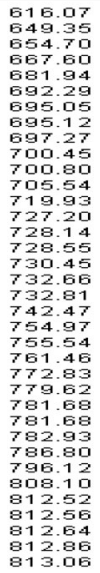 & 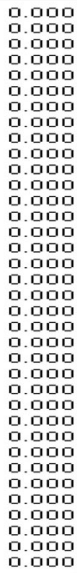 \\
\hline
\end{tabular}

Fig. 8 Correlogram of KOTAK GETF. The correlogram displays a character-based plot of the Autocorrelations, Partial autocorrelations and the Portmanteau (Q) statistics of the difference in log price of KOTAK GETF

gave rise to a current-account deficit of 5.4\% of the GDP in 2012. It is worth noting that Indians, either directly or indirectly, own an estimated 22,000 t of gold worth $\$ 800$ billion - approximately 39\% of India's GDP. This growing appetite of Indians for gold is largely met by imports, which accounted for about $1.7 \%$ of the GDP in the fiscal year 2015-16 and drove the current-account deficit up to 1.4\% of GDP. It was also estimated that if India's gold buyers were to pour their annual savings into other investment instruments, such as shares, mutual funds or property, the country's annual GDP would be $0.4 \%$ higher. Recently, the volume of gold imports has risen steeply, regardless of the fast increase in gold prices. This suggests that India's gold imports are comparatively price inelastic. The demand for gold investing decreased GDP by $-1.9 \%$ in the fiscal year 2016-17.

India is flourishing economically and achieving progress among other developing countries in terms of having a lucrative market for exchange-traded derivatives. This

\begin{tabular}{|c|c|c|c|c|c|}
\hline Autocarrelation & Partial correlation & $A C$ & PAC & a-stat & Prob \\
\hline (:'s & 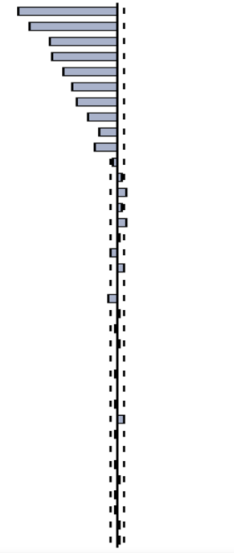 & 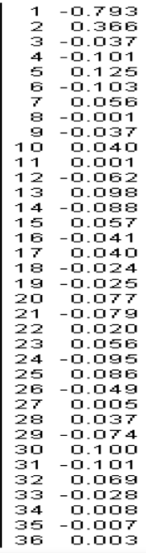 & 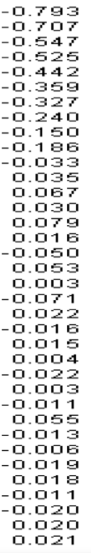 & 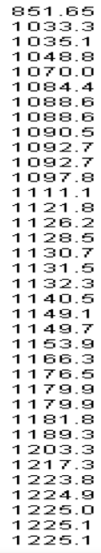 & 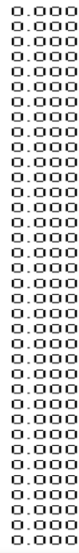 \\
\hline
\end{tabular}

Fig. 9 Correlogram of R*SHARES GETF. The correlogram displays a character-based plot of the Autocorrelations, Partial autocorrelations and the Portmanteau (Q) statistics of the difference in log price of $R^{*}$ SHARES GETF 


\begin{tabular}{|c|c|c|c|c|c|c|}
\hline Autocarrelation & Partial correlation & & AO & PAC & Q-Stat & Prab \\
\hline 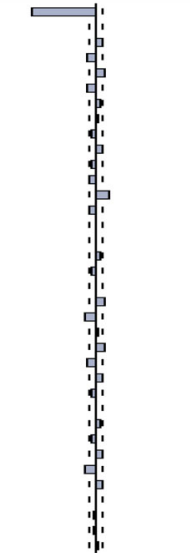 & 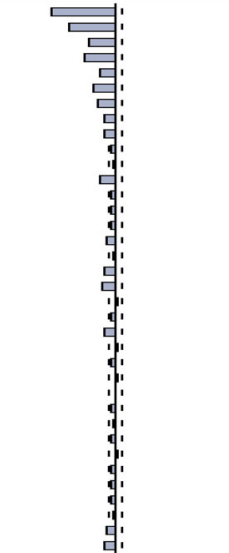 & $\begin{array}{l}1 \\
2 \\
3 \\
4 \\
5 \\
6 \\
7 \\
8 \\
9 \\
10 \\
11 \\
12 \\
13 \\
14 \\
15 \\
16 \\
17 \\
18 \\
19 \\
20 \\
21 \\
22 \\
23 \\
24 \\
25 \\
26 \\
27 \\
28 \\
29 \\
30 \\
31 \\
32 \\
33 \\
34 \\
35 \\
36\end{array}$ & $\begin{array}{r}-0.527 \\
0.005 \\
0.059 \\
-0.079 \\
0.081 \\
-0.073 \\
0.040 \\
0.015 \\
-0.032 \\
-0.043 \\
-0.030 \\
-0.055 \\
0.101 \\
-0.057 \\
0.008 \\
-0.008 \\
-0.031 \\
-0.045 \\
0.008 \\
0.081 \\
-0.095 \\
0.018 \\
0.070 \\
-0.079 \\
0.050 \\
-0.035 \\
-0.002 \\
0.028 \\
-0.035 \\
0.065 \\
-9.037 \\
0.047 \\
0.007 \\
-0.018 \\
-0.018 \\
0.020\end{array}$ & $\begin{array}{l}-0.527 \\
-0.379 \\
-0.221 \\
-0.247 \\
-0.137 \\
-0.180 \\
-0.143 \\
-0.096 \\
-0.093 \\
-0.033 \\
-0.021 \\
-0.129 \\
-0.041 \\
-0.046 \\
-0.048 \\
-0.079 \\
-0.020 \\
-0.083 \\
-0.109 \\
0.011 \\
-0.045 \\
-0.088 \\
0.011 \\
-0.028 \\
0.017 \\
-0.004 \\
-0.035 \\
-0.024 \\
-0.039 \\
0.023 \\
-0.045 \\
-0.029 \\
-0.044 \\
-0.021 \\
-0.070 \\
-0.084\end{array}$ & 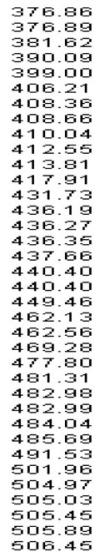 & $\begin{array}{l}\text { O.000 } \\
0.000 \\
0.000 \\
0.000 \\
0.000 \\
0.000 \\
0.000 \\
0.000 \\
0.000 \\
0.000 \\
0.000 \\
0.000 \\
0.000 \\
0.000 \\
0.000 \\
0.000 \\
0.000 \\
0.000 \\
0.000 \\
0.000 \\
0.000 \\
0.000 \\
0.000 \\
0.000 \\
0.000 \\
0.000 \\
0.000 \\
0.000 \\
0.000 \\
0.000 \\
0.000 \\
0.000 \\
0.000 \\
0.000\end{array}$ \\
\hline
\end{tabular}

Fig. 10 Correlogram of UTI GETF. The correlogram displays a character-based plot of the Autocorrelations, Partial autocorrelations and the Portmanteau (Q) statistics of the difference in log price of UTI GETF

recapitulates the efficacy of the progressive initiations in India's securities markets, which are based on countrywide means of market entry, incognito electronic trading, and a pre-eminent retail market. This derivative has been trading on the National Stock Exchange of India for a considerable period of time. The purpose of their introduction has been met as they facilitate Indian households' in the bullion market in very small denominations. Hence one may speculate that as of today, the Indian GETF market has become informationally efficient no fund manager is able to beat the market and make supernormal profits. However, the literature addressing the price discovery mechanism of the Indian GETFs since its introduction is scarce. There is overwhelming evidence that the Indian GETF market is weak-form efficient (Saji, 2014). Findings concerning weak-form efficiency of the gold market returns in India are, nevertheless, conflicting (Ntim et al., 2015). Like other emerging economies, India had to face the negative impact crises and experienced turbulent stock markets and currency fluctuations, especially during 2008-10. Increasing inflationary pressures can cause local currencies to become less appealing and boost the demand for gold, thus causing an upsurge in gold price volatility (Wang et al., 2011; Wei et al., 2011). This paper analyzes the Indian GETF market for five consecutive years after 2010 and using the daily returns of five GETFs, strives to provide evidence concerning the efficiency of the Indian GETF market.

Table 3 Probability values of the unit root test

\begin{tabular}{|c|c|c|c|c|c|c|}
\hline \multirow[t]{2}{*}{ GETF } & \multicolumn{2}{|l|}{ NONE } & \multicolumn{2}{|l|}{ INTERCEPT } & \multicolumn{2}{|c|}{ TREND \& INTERCEPT } \\
\hline & Coefficient & $P$ value & Coefficient & $P$ value & Coefficient & $P$ value \\
\hline GOLDMAN SACHS & -0.9778 & $0.0000 * *$ & -0.9785 & $0.0000 * *$ & -0.9831 & $0.0000 * *$ \\
\hline KOTAK & -1.0048 & $0.0000 * *$ & -1.0051 & $0.0000 * *$ & -1.0083 & $0.0000 * *$ \\
\hline$R^{*}$ SHARES & -1.0453 & $0.0000 * *$ & -1.0459 & $0.0000 * *$ & -1.0486 & $0.0000 * *$ \\
\hline SBI & -1.0409 & $0.0000 * *$ & -1.0416 & $0.0000 * *$ & -1.0449 & $0.0000 * *$ \\
\hline UTI & -0.9856 & $0.0000 * *$ & -0.9821 & $0.0000 * *$ & -0.9852 & $0.0000 * *$ \\
\hline
\end{tabular}

$\left({ }^{* *}\right)$ Significant at $5 \%$ level 
The results of the runs test, serial correlation test, and ADF test coincide at the 5\% level of significance and reveal that the GETF return data under analysis, calculated as differences in log-transformed closing prices, are not random and are stationary in nature. This leads to the excogitation that subsequent changes in historical prices can be used to estimate future price changes, and supports the conclusion that historic GETF prices influence the derivative's future prices.

Overall, the results of the tests provide evidence against weak-form efficiency in the GETF market. Both the non-parametric and parametric tests for the presence of a unit root in the GETF returns as well as the correlogram patterns do not validate the presence of a unit root in the time series data under analysis. The results of the runs test reveal that the prices are stationary in nature. In particular, the serial correlation test demonstrates that for the majority of the GETFs in the sample, returns are not random. The autocorrelation test substantiates the findings on the inefficiency of the GETF market. In the autocorrelation plots for all five GETFs under analysis, the length of the correlogram bars gradually decreases and becomes zero or nearly zero, indicating that the data under analysis are stationary. This is interpreted as a failure in the price discovery mechanism and leads to the dismissal of the conjecture that the Indian GETF market is weak-form efficient.

However, auto-correlation in the daily returns does not automatically mean rejection of weak-form efficiency, the finding supports the idea that the returns in Indian GETF market are predictable. Hence, it is up to the regulatory board to intervene in order to prevent bias and enhance the nationwide market conditions to boost savings and investment. In the event of a market decline, the government needs to interfere in order to steer the market into the path toward more economic development. Fund managers and regulatory bodies may note that pursuing active investment strategies may be effective in achieving market efficiency because in doing so the latest available information is revealed in the prices of GETFs. A study on the US ETF market compared the impact of active and passive investment strategies on market efficiency and found that active management contributes more to improving market efficiency while helping incorporate information into prices (Chen et al., 2013).

Further, based on the unit root test, the time series data does not follow a random walk. This means that there is information asymmetry present in the market and contorted information alters price formation. Unenlightened fund managers form erroneous estimates of GETF units' prices distorting thus the efficiency of the price discovery mechanism. The curtailed information may instigate two other occurrences - adverse selection and moral hazard that will diminish market efficiency.

The rejection of the null hypothesis that the market is not efficient in its weak form can be attributed to the eccentricities pertaining to the price-forming information on Indian GETF derivatives market and to the barriers to the rapid dissemination of information, such as the lack of up-to-date telecommunications infrastructure, paucity of business journals and unavailability of more scrupulous market guidelines.

One of the possible reasons for the inefficiency of the GETF market in India is the herd behavior of investors, characterized by the fear of missing an opportunity and by the market uncertainties that motivate traders and investors to behave frantically. Consequently, the role of policy makers in the GETF market is to prudently balance the market and ensure smoother price discovery process. 
Although this paper presents evidence of return predictability in the Indian GETF market, it remains unknown whether is economically profitable to exploit this predictability same when weighed up against the underlying costs, such as transaction costs. Fund managers may look for arbitrage opportunities capable of delivering excess risk-adjusted returns. Future studies may supplement these results by evaluating the economic feasibility of investment strategies aimed at exploiting such predictability-related opportunities.

It is vitally important for ETFs to have rigid norms for gold lending to eradicate or curtail counterparty risk. Despite stringent lending norms, as soon as gold is lent, it disseminates and the mechanism of restocking it entails complications to the fund. Moreover, GETFs can lend to bullion banks that can, in turn, lend to jewelers. Taking one-step ahead would be if GETFs were permitted to lend gold only by way of stock exchanges via their stock lending/borrowing mechanism. Stock exchanges are currently not endowed with facilities to handle physical gold, but handling can be made feasible by forming alliances with gold-vaulting agents. Gold lending and borrowing by means of stock exchanges will ensure more transparency, better price discovery and lower counterparty risk.

Any market action that results in market failure signals the need to restrict market access for some traders, particularly speculators, but such situations are preventable with appropriately designed legislation. The disruptive role of speculators is said to have altered the price discovery of GETFs on the market.

Additional work is needed to examine whether the characteristics of GETF prices can be attributed to anomalies or whether they are indicative of changes in the market's structure and performance that may alter the derivative's comprehensibility in the future.

\section{Conclusion}

The tests of stationarity employed in this paper suggest, that the daily price changes are not arbitrary and the logarithm difference series of closing prices are stationary. Thus, the respective GETF prices in the last the period 2010-2015 do not follow a random walk. They do exhibit some serial correlation, which allows for future prices to be estimated using suitable forecasting techniques. In an efficient market, however, historical prices are not useful in predicting the future, the price changes are supposed to be random in nature. The current paper's results confirm that the price discovery on the considered derivative market is not happening as expected, the conclusion being that the GETF market in India is not weak form efficient. As in any other emerging market, market efficiency, of course, cannot be expected in an early stage of the market's development (Srivastav, 2013). Further, GETF prices depend on the value of the underlying asset in the bullion market, so the information asymmetries in the bullion market come into play in the GETF market as well. Hence, investors can make abnormal profits (i.e., arbitrage opportunities may exist). Although GETFs are generally an efficient investment instrument, their price discovery mechanism seems to be failing due to factors introducing, inefficiency into this security market. However, by imposing stringent regulations, regulatory bodies can avert information asymmetries. Measures introduced by policy makers to stabilize the Indian GETF market would be expected to promote a successful price discovery mechanism for the derivative and, thus, aid in achieving efficiency of the Indian GETF market. 


\section{Acknowledgements}

Only the authors worked upon this paper and there were no other individuals who have contributed towards this article.

\section{Funding}

There was no funding involved in the design of study, data collection, analysis and interpretation as this research was a part of the curriculum of M.Sc. Actuarial Science in B S Abdur Rahman University.

\section{Authors' contributions}

The subject MAB7103 - Financial Economics was a part of the curriculum of the M.Sc. Actuarial Science course in B S Abdur Rahman University. Dr. AN handled the subject. As a requirement for the course, a term paper on Market Efficiency was prepared and the course teacher encouraged and motivated me (RN) for preparing it as a journal paper. I (RN) did the data collection and analysis and Dr. AN guided on its interpretation and corrected the paper in making it suitable for publication. Both authors read and approved the final manuscript.

\section{Competing interests}

The authors do not have any financial competing interest in the publication of this paper. This research was done solely for academic purposes alone.

\section{Publisher's Note}

Springer Nature remains neutral with regard to jurisdictional claims in published maps and institutional affiliations.

\section{Author details}

'Department of Mathematics and Actuarial Science, B S Abdur Rahman Crescent University, Chennai 600048, India. 2Department of Management Studies, B S Abdur Rahman Crescent University, Chennai 600048, India.

Received: 23 July 2016 Accepted: 8 August 2017

Published online: 25 August 2017

\section{References}

Aggarwal R, Lucey BM, O'Connor FA (2014) Rationality in precious metals forward markets: evidence of behavioural deviations in the gold markets. J Multinational Financial Manag 25-26:110-130

Aggarwal R, Schofield L (2013) The growth of global ETFs and regulatory challenges. Advances Financial Economics, Emerald books:77-100

Aggarwal R, Soenen LA (1988) The nature and efficiency of the gold market. J Portfolio manag 14(3):18-21

Arouri MEH, Hammoudeh S, Lahiani A, Nguyen DK (2012) Long memory and structural breaks in modeling the return and volatility dynamics of precious metals. Quarterly Rev Economics Finance 52(2):207-218

Artigas JC (2010) Rediscovering gold as an asset class debt be not proud. Journal of indexes 13(6):10-17

Batten JA, Ciner C, Lucey BM (2010) The macroeconomic determinants of volatility in precious metals markets. Res Policy 35(2):65-71

Batten JA, Ciner C, Lucey BM (2014) On the economic determinants of the gold-inflation relation. Resources Policy $41(C): 101-108$

Baur D G (2013) Exchange-traded funds on gold-a free lunch? FIRN research paper, doi:ssrn.2297756

Baur DG, McDermott TK (2010) Is gold a safe haven? International evidence. J Banking Finance 34(8):1886-1898

Bodie Z, Kane A, Marcus AJ (2007) Essentials of investments, 6th edn. McGraw- Hill / Irwin, Boston

Bradley J V (1968) Distribution-free statistical tests. Prentice Hall

Brealey RA, Myers SC, Marcus AJ (1999) Fundamentals of corporate finance, 2nd edn. McGraw-Hill, USA

Cai J, Cheung YL, Wong M (2001) What moves the gold market? J Futur Mark 21(3):257-278

Charles A, Darné O, Kim JH (2015) Will precious metals shine? A market efficiency perspective. Inter Rev Financial Anal $41(C): 284-291$

Chen T, Wang KHY, Susan M (2013) (2013) which improves market efficiency of ETFs : active or passive management? In: international conference on information and social science \& international symposium on marketing. logistics and business, Open University of Hong Kong, HK, pp 24-26

Cheung YW, Lai KS (1993) Do gold market returns have long memory? Financial Rev 28(2):181-202

Ciner C (2001) On the long-run relationship between gold and silver: a note. Global Finance Journal 12(2):299-303

Damodar N G (2003) Basic econometrics. Mc-Graw Hill

Daskalaki C, Skiadopoulos G (2011) Should investors include commodities in their portfolios after all? New evidence. J Banking Finance 35(10):2606-2626

Domanski D, Heath A (2007) Financial investors and commodity markets. BIS quarterly review, March, 53-67. https:// ssrn.com/abstract=1600058

Elango R, Hussein MI (2008) An empirical analysis on the weak-form efficiency of the GCC markets applying selected statistical tests. International Rev Bus Res Papers 4(1):140-159

Enders W (2008) Applied econometric time series. Wiley.

Eswara M (2015) An empirical study on performance of gold ETFs in India-post crash period. doi:10.2139/ssrn.2679686 Fama EF (1970) Efficient capital markets: a review of theory and empirical work. J Financ 25(2):383-417

Goodman B (1956) The price of gold and international liquidity. J Finance 11(1):15-28

Goyal A, Joshi A (2011) Performance appraisal of gold ETFS in India. Journal of elixir finance 32:2057-2060

Goyal MM (2014) Accelerating growth of GETF in India. International Journal of Innovative Res Development 3(10):206-210 Gupta R, Basu PK (2011) Weak form efficiency in Indian stock markets. International Business and Economics Research Journal 6(3):57-64 
Hassan A, Abdullah MS, Shah ZA (2007) Testing of random walks and market efficiency in an emerging market: an empirical analysis of karachi stock exchange. The business review, Cambridge 9(1):271-280

Lashgari MK (1992) Information from successive changes in gold and silver prices during phases of the business cycles. Journal Economics Finance 16(2):13-30

Malkiel BG, Fama EF (1970) Efficient capital markets: a review of theory and empirical work. J Financ 25(2):383-417 Mukesh M, Vikrant K, Sougata R (2012) GETF performance: a comparative analysis of monthly returns. IUP journal of financial risk management 9(2):59-63

Narend S, Thenmozhi M (2014). Performance and price discovery of gold exchange traded funds. doi:10.2139/ssrn. 2370337

Naylor M, Wongchoti U, Gianotti C (2011) Abnormal returns in gold and silver exchange traded funds. Journal of index investing 2(2):96-103

Ntim CG, English J, Nwachukwu J, Wang Y (2015) On the efficiency of the global gold markets. Int Rev Financial Analy $41(\mathrm{C}): 218-236$

Reddy YV, Wagle MNS, Naik MMS (2014) Performance evaluation of gold exchange traded funds listed on NSE. Amity Case Res J 3:60-65

Saji TG (2014) Weak form efficiency of gold ETF markets: an empirical note from India. J Economic Policy Res 10(1):136-150 Sazonov W, Nikolaev DV (2013) Theoretical aspects of investment demand for gold. Investment Management Financial Innovations Journal 10(4):42-49

Shafiee S, Topal E (2010) An overview of global gold market and gold price forecasting. Resources policy 35(3):178-189

Solt ME, Swanson PJ (1981) On the efficiency of the markets for gold and silver. J Bus 54(3):453-478

Srivastav VK (2013) Efficiency in Indian commodity market. Paradigm 17(1-2):105-110

Umarani R, Deepa D (2015) Investors awareness of gold exchange traded fund in India. Global J Res Analysis 4(7):196-198

Velmurugan PS, Saravanan A, Raghavendra R (2013) A comparative study on investing in gold related assets. Elk Asia Pacific J Finance Risk Manag 4(1):ISSN-2349-ISSN-2325

Wang KM, Lee YM, Thi TBN (2011) Time and place where gold acts as an inflation hedge: an application of long-run and short-run threshold model. Econ Model 28(3):806-819

Wei Y, Wang Y, Wu C (2011) Analysis of the efficiency and multifractality of gold markets based on multifractaldetrended fluctuation analysis. Physica A: Stat Mechanics Applications 390(5):817-827

World Gold Council (2008). World Gold Council Publications Archive. www.gold.org

Worthington AC, Higgs H (2006) Evaluating financial development in emerging capital markets with efficiency benchmarks. J Economic Development 31(1):17-44

Submit your manuscript to a SpringerOpen ${ }^{\circ}$ journal and benefit from:

- Convenient online submission

- Rigorous peer review

Open access: articles freely available online

- High visibility within the field

- Retaining the copyright to your article

Submit your next manuscript at $>$ springeropen.com 